\title{
Farklı Ketencik [Camelina sativa (L.) Crantz.] Genotiplerinin Ham Yăg Oranları ve Yă̆ Asitleri Kompozisyonlarının Belirlenmesi
}

\author{
Merve GÖRE ${ }^{1}$ \\ Orhan KURT ${ }^{1}$ \\ ${ }^{1}$ Ondokuz Mayıs Üniversitesi, Ziraat Fakültesi, Tarla Bitkileri Bölümü, Atakum, Samsun \\ $\triangle$ : merve.gore@omu.edu.tr
}

Geliş (Received): 03.11.2017

Kabul (Accepted): 15.12.2017

\begin{abstract}
ÖZET: Bu Araştırma; Samsun ekolojik koşullarında 12 ketencik genotipinin ham yağ oranları ve yă̆ asidi kompozisyonlarının belirlenmesi amacıyla, 2014-2015 ve 2015-2016 yıllarında, Ondokuz Mayıs Üniversitesi, Ziraat Fakültesinde yürütülmüştür. Araştırma sonucu; ham yağ oranları ile palmitik, stearik, oleik, linoleik, linolenik, araşidik, eikosenoik ve erusik yağ asitleri kompozisyonu bakımından genotipler arasında istatistiki anlamda önemli farklılığın olduğu tespit edilmiştir. İki yılın ortalaması olarak; ham yağ oranının \%28.48-36.09 olduğu, palmitik asit oranının \%6.28-7.35, stearik asit oranının \%2.43-2.77, oleik asit oranının \%14.78-17.22, linoleik asit oranının \%16.04-20.33, linolenik asit oranının \%36.07-40.13, araşidik asit oranının \%1.34-2.17, eikosenoic (gondoic) asit oranının \%15.65-18.16 ve erusic asit oranının \%0.38-0.60 arasında değiştiği belirlenmiştir. Sonuç olarak en yüksek ham yağ oranına sahip genotipin Ames-26686 olduğu; oleik asiti yüksek ve yağın yemeklik kalitesini yükseltmek amacıyla çalışmalarda yer alabilecek ketencik genotipinin CR-1674190 olduğu, Linoleik asit oranı bakımından yerli, Omega-3 kaynağı olarak kullanılacak ketencik genotipi olarak Ames-26665 genotipi olduğu ve erusic asit içeriği bakımından da en düşük erusik asit oranına sahip genotipin CR-476/65 olduğu belirlenmiştir. Dolayısıyla yapılacak çalışmalarda bu genotipler üzerinde durulmasının uygun olduğu sonucuna varılmıştır.
\end{abstract}

Anahtar Kelimeler: Ketencik, Ham Yağ Oran1, Yağ Asidi Kompozisyonu

\section{Determination of Crude Oil Contenta and Fatty Acid Composition of Different False Flax [Camelina sativa (L.) Crantz.] Genotypes}

\begin{abstract}
This Research; in order to determine the crude oil contents and fatty acid compositions of the 12 false flax genotypes in the Samsun ecological conditions, it was carried out at the Faculty of Agriculture, Ondokuz Mayis University in 2014-2015 and 2015-2016. Research result; crude oil contents and palmitic, stearic, oleic, linoleic, linolenic, arachidic, eicosenoic and erusic fatty acids were statistically significant differences between the genotypes in terms of composition. As averages of two years; crude oil ratio was found to be 28.48-36.09\%. In addition, the content of palmitic acid was 6.28-7.35\%, the content of stearic acid 2.43-2.77\%, the content of oleic acid 14.78$17.22 \%$, the content of linoleic acid $16.04-20.33 \%$, the content of linolenic acid $36.07-40.13 \%$, the content of arachidic acid $1.34-2.17 \%$, eicosenoic (Gondoic) acid ratio of between $15.65-18.16 \%$ and the erusic acid ratio of between 0.38 and $0.60 \%$. As a result, the genotype having the highest crude oil ratio was Ames-26686; it is known that the falsa flax genotype which is high in oleic acid and high in oil cooking quality is CR-1674190, it is locus in terms of linoleic acid ratio and ames-26665 genotype in false flax genotype to be used as omega- 3 source and the lowest erucic acid ratio in terms of erucic acid content has been identified as having the genotype CR-476/65. Therefore, it has come to the conclusion that it is appropriate to focus on these genotypes in the works to be done.

Keywords: Falseflax, Crude Oil Content, Fatty Acid Composition
\end{abstract}

\section{GíRiș}

Artan dünya nüfusuna paralel olarak bitkisel yă̆ tüketiminin de artması ile yağlı tohumlu bitkiler Dünyada ve ülkemizde stratejik öneme sahip bitkiler konumuna gelmiştir (Kurt ve ark., 2015). Bitkisel yağ açığımızın kapatılması ve enerji ihtiyacımızın karşılanması için hala hazırda ekilmekte olan yağ bitkilerinin yanında aynı amaçları tamamen veya kısmen karşılama potansiyeli olan yağ bitkilerinin üretim desenimize en kısa zamanda entegre edilmesi gerekir.

Ketencik; kaliteli ve değerli yağı, enerji yakıtı (biyojet) olarak kullanılmasındaki yeri, kısa vejetasyon süresi ile üreticiye üretim çeşitlendirilmesindeki yüksek getirisi, münavebe sisteminde yer almasındaki avantajları, yabancı ot rekabetinin yüksek olması, toprak isteğinin az olması gibi sebeplerle yağ bitkileri arasında önemli bir potansiyele sahiptir.

Ketencik yağında yaklaşık \%90-95 doymamış yağ asitleri ve \%5-10 doymuş yağ yer alır. Doymamış yağ asitlerinin \%60'lık kısmını; çoklu doymamış yağ asitleri oluşturmakta olup, linolenik asit oranı $\% 35-45$, linoleik asit oranı \%15-20 civarındadır. Tekli doymamış yağ asitlerinin oranı yaklaşık \%36 olup bu yă asitleri öncelikle oleik asit ve eicosenoik asitten oluşmaktadır. Ketencik çeşitlerinin çoğu \%2-4 erusik asit (C22:1n-9) içermekte olup, $\% 0$ erusik asit ihtiva eden ketencik çeşitleri de son yıllarda geliştirilmiştir.

Camelina yağının kimyasal bileşimi genetik faktörlerin yanında toprak, iklim ve çevre koşulları gibi kontrol edilemeyen birçok faktör tarafindan büyük ölçüde etkilenir. $\mathrm{Bu}$ düşünceden hareketle Samsun ekolojik koşullarında farklı ketencik genotiplerinin ham 
yağ oranı ve yağ asitleri kompozisyonunun belirlenmesi amaciyla bu araştırma yürütülmüştür.

\section{MATERYAL ve YÖNTEM}

\section{Araştırma Yeri Hakkında Genel Bilgiler}

Tarla denemesi, Ondokuz Mayıs Üniversitesi, Ziraat Fakültesi, deneme alanında yürütülmüsşür. Deneme alanının toprakları killi (ağır), organik maddece zayıf, tuzsuz ve yüzlek bir yapıda olup, denizden yüksekliği 120 metredir. Deneme alanında, yetiştirme sezonunda 1. yıl $(657,5 \mathrm{~mm})$ ve 2 . yıl $(658.4 \mathrm{~mm})$ yağış miktarları uzun yilların ortalamasından $(502.2 \mathrm{~mm})$ fazla olduğu, 1. yıl $\left(12.1^{\circ} \mathrm{C}\right)$ ve 2 . yıl $\left(12.9^{\circ} \mathrm{C}\right)$ sicaklık ortalamaları uzun yılların ortalamasından $\left(11.4^{\circ} \mathrm{C}\right)$ daha yüksektir.

\section{Materyal ve Yöntem}

Araştırmada bitki materyali olarak 12 farklı ketencik genotipi (Ames 26665, Ames 26667, Ames 28372, Ames 26673, Ames 26676, Ames 26680, Ames 26686, CR-1674190, CR 476/65, PI 304269, Vniimk-17 ve Yerli) kullanılmıştır. Genotip, Tesadüf Blokları Deneme Desenine göre 4 tekerrürlü olarak sıra uzunluğu 3 metre, sıra arası $20 \mathrm{~cm}$ ve her genotip 5 sira olacak şekilde, 1 . yll 12 Aralık 2014 ve 2. y1l 26 Kasım 2015 tarihinde, elle ekilmiştir. Hasat, tam olgunluğa erişme aşamasında olmak üzere her bir hat için ayrı ayrı olacak biçimde yapılmıştır. Harman sonrası her bir hatta ait tohumlardan ham yağ analizi Ankom XT15 extractor cihazı kullanılarak (Anon, 2017), yağ asidi kompozisyonu ise GC-MS cihazı kullanılarak (Kurt ve ark., 2011) yapılmıştır. Araştırmadan elde edilen verilerin değerlendirilmesinde SPSS programı kullanılmıştır. Varyans analiz tablolarına göre önemli çıkan uygulamalar arasındaki farklılıklar DUNCAN çoklu karşılaştırma testine göre gruplandırılmıştır.

\section{BULGULAR ve TARTIŞMA}

Ham Yăg Oranı: Araştırma sonucu ham yağ oranının ilk yll \%36.55 ve ikinci yll \%28,28 ve iki yilın ortalaması olarak da \%32.41 olduğu belirlenmiştir. Genotip bazında değerlendirildiğinde; 2015 yılında en yüksek ham yăg oranı $\% 37.85$ ile PI-304269 genotipinden, en az ham yağ oran1 \%31.08 ile Vniimk17 genotipinden elde edilmiştir. 2016 yllı en yüksek ham yağ oran1 \%34.35 ile Ames-26686 genotipinden, en az ham yağ oranı \%23.68 ile CR-1674190 genotipinden elde edilmiştir. İki yılın ortalaması olarak en yüksek ham yağ oran1 \%36.09 ile Ames-26686 genotipinden, en az ham yağ oranı \%28.48 ile Vniimk-17 genotipinden elde edilmiştir (Çizelge 1).

Ketencik bitkisinde daha önce yapılan bazı çalışmalarla ham yağ oranının \%29,9-38,3 (Budin ve ark.,1995) ve \%29,0-39,0 (Vollmann, 1996) arasinda değiştiği, gübre uygulamasında yă̆ oranının \%31 olduğu (Karahoca, 2002), ekim zamanlarına bağl olarak ham yağ oranının \%25,2-37,2 arasında değiştiği (Katar ve ark., 2012) yönündeki bulgular bu araştırmada elde edilen bulgularla paralellik arz etmesine karşın ham yağ oranının daha yüksek olduğunun tespit edildiği bazı çalışmalarla uyum arz etmemektedir. Şöyle ki
İskandinavya farklı lokasyonlarda ham yağ oranının \%39,6-44,1 (Zubr, 2003) olduğu, ekim zamanlarına bağlı olarak ham yağ oranının \% 42,0-45,7 arasında değiştiği (Berti ve ark., 2011), gübre uygulaması sonucu ham yağ oranının \%37,1-39,8 arasında değiştiği (Tomas ve ark., 2011) bildirilmektedir. Bu farklılık; genotipik faktörlerin yanında bu araştırmanın yapıldığı toprakların ihtiva ettiği fosfor miktarının az olması, araştırma alanında ortalama sıcaklığın daha yüksek olması ve çiçeklenme ve kapsül oluşumu dönemlerindeki sıcaklık artışlarının sonucu olarak ortaya çıkmış olabilir.

Doymuş ve Doymamış Yağ Asitleri Kompozisyonu: Araştırma sonucu doymuş yağ asitlerinin oranının ilk yıl $\% 8.55$, ikinci yıl $\% 9.99$ ve iki yılın ortalaması olarak $\% 9.26$ olduğu, doymamış yağ asit oranının ise ilk yıl $\% 91.45$, ikinci y1 \%90,01 ve iki yllın ortalaması olarak $\% 90,74$ olduğu tespit edilmiştir. Genotip bazında değerlendirildiğinde; en yüksek doymuş yağ asidi oranı ilk yl \%8.91 ile Ames 28372 genotipinden, ikinci yıl \%11.20 ile Ames 26676 genotipinden ve iki yilın ortalaması olarak \%10.00 ile Ames 26676 genotipinden elde edilmiştir. En yüksek doymamış yağ asidi oranı ise ilk y1 \%91.88 ile Ames 26673 genotipinden, ikinci y1 $\% 90.94$ ile yerli genotipinden ve iki yllın ortalaması olarak \%91.21 ile Ames 26686 genotipinden elde edilmiştir (Çizelge 1).

Ketencikte daha önce yapılan çalışmalarda; doymuş yağ asidi oranının \%8.00 (Agegnehu ve Honermeier,1997) ve \%12.00 (Angelini ve ark., 1997) olduğu, doymamış yă asitlerinin oranının \%92.00 (Agegnehu ve Honermeier,1997) ve \%88 (Angelini ve ark., 1997) olduğu bildirilmiştir ki bu araştırmada elde edilen sonuçlarla da benzerlik göstermektedir.

Yă̆ Asitleri Kompozisyonu: Palmitik asit oranının, ortalama olarak ilk yıl \%5.96, ikinci yıl \%7.37 ve iki yılın ortalaması olarak \%6.66 olduğu belirlenmiştir. Genotip bazında değerlendirildiğinde; 2015 yılında en yüksek palmitik asit oranına \%6.38 ile Ames-28372 genotipinden, en düşük palmitk asit oranın \%5.57 ile Ames-26673 genotipinden elde edilmiştir. 2016 yllinda en yüksek palmitik asit oranı \%8.76 ile Ames-26676 genotipinden,en düşük palmitik asit oranı $\% 6.42$ ile Yerli genotipinden elde ediliştir. İki yılın ortalaması olarak en yüksek palmitik asit oran1 \%7.35 ile Ames26676 genotipinden, en düşük palmitik asit oranı $\% 6.28$ ile Ames-26686 genotipinden elde edilmiştir (Çizelge 1).

Stearik asit oranının, ortalama olarak ilk yıl \%2.59, ikinci y1 $\% 2.62$ ve iki y1lın ortalaması olarak \%2.60 olduğu belirlenmiş̧tir. Genotip bazında değerlendirildiğinde; 2015 yllında en yüksek stearik asit oranına \%2.85 ile Ames-26676 genotipinden, en düşük stearik asit oranın \%5.57 ile Ames-26686 genotipinden elde edilmiş̧ir. 2016 yılında en yüksek stearik asit oranı \%2.84 ile Ames-26673 genotipinden, en düşük stearik asit oran1 \%2.44 ile Ames-26676 genotipinden elde ediliştir. İki yılın ortalaması olarak en yüksek stearik asit oran1 \%2.77 ile PI-304269 genotipinden, en düşük stearik asit oran $1 \% 2.43$ ile Ames-26680 genotipinden elde edilmiştir (Çizelge 1).. 
Çizelge 1. İncelenen genotiplerin ham yağ oranı ile, yağ asitlerinden palmitik asit, stearik asit, oleik asit, linoleik asit, linolenik asit, eicosenoik asit, araşidik asit ve erusik asit oranlarına ilişkin veriler

\begin{tabular}{|c|c|c|c|c|c|c|c|c|c|}
\hline \multirow[b]{3}{*}{ Genotipler } & \multirow{2}{*}{\multicolumn{3}{|c|}{ Ham Yağ oranı (\%) }} & \multicolumn{6}{|c|}{ Yağ Asitleri Kompozisyonu (\%) } \\
\hline & & & & \multicolumn{3}{|c|}{ Palmitik Asit } & \multicolumn{3}{|c|}{ Stearik Asit } \\
\hline & 2015 & 2016 & Ort. & 2015 & 2016 & Ort. & 2015 & 2016 & Ortalama \\
\hline Ames 26686 & 37,84 & $34,35 \mathrm{a}$ & $36,09 \mathrm{a}$ & $5,89 \mathrm{def}$ & $6,67 \mathrm{f}$ & $6,28 \mathrm{e}$ & $2,37 \mathrm{~g}$ & $2,65 a-c$ & $2,51 \mathrm{de}$ \\
\hline Vniimk 17 & 31,08 & $25,89 \mathrm{c}$ & $28,48 \mathrm{~d}$ & $6,10 \mathrm{bc}$ & $6,51 \mathrm{f}$ & $6,30 \mathrm{e}$ & $2,43 \mathrm{f}$ & $2,74 \mathrm{abc}$ & $2,59 \mathrm{bcd}$ \\
\hline CR 1674190 & 37,49 & $23,68 \mathrm{c}$ & $30,58 \mathrm{~cd}$ & $5,73 \mathrm{efg}$ & $7,49 \mathrm{c}$ & $6,61 \mathrm{~d}$ & $2,60 \mathrm{~d}$ & $2,54 \mathrm{cc}$ & $2,57 \mathrm{~cd}$ \\
\hline Ames 26673 & 36,32 & $26,22 \mathrm{bc}$ & $31,27 \mathrm{bcd}$ & $5,57 \mathrm{~g}$ & $7,18 \mathrm{~d}$ & $6,38 \mathrm{e}$ & $2,55 \mathrm{e}$ & 2,84 & $2,69 \mathrm{ab}$ \\
\hline Ames 26676 & 36,59 & $27,34 \mathrm{bc}$ & $31,96 \mathrm{bc}$ & $5,93 \mathrm{cde}$ & $8,76 \mathrm{a}$ & $7,35 \mathrm{a}$ & $2,85 \mathrm{a}$ & $2,44 c$ & $2,65 \mathrm{bc}$ \\
\hline Ames 26680 & 37,83 & $28,53 \mathrm{bc}$ & $33,18 \mathrm{abc}$ & $6,22 \mathrm{ab}$ & $8,05 \mathrm{~b}$ & $7,13 b$ & $2,64 \mathrm{c}$ & 2,226 & $2,43 \mathrm{e}$ \\
\hline Ames 28372 & 37,34 & $26,94 \mathrm{bc}$ & $32,14 \mathrm{bc}$ & $6,38 \mathrm{a}$ & $7,43 \mathrm{c}$ & $6,90 \mathrm{c}$ & $2,53 \mathrm{e}$ & $2,63 a-c$ & $2,58 \mathrm{bcd}$ \\
\hline Ames 26665 & 35,18 & $27,18 \mathrm{bc}$ & $31,18 \mathrm{bcd}$ & $6,03 \mathrm{bcd}$ & $6,66 \mathrm{ef}$ & $6,34 \mathrm{e}$ & $2,61 \mathrm{~d}$ & $2,59 \mathrm{bcc}$ & $2,60 \mathrm{bcd}$ \\
\hline Ames 26667 & 36,63 & $29,49 \mathrm{bc}$ & $33,06 \mathrm{abc}$ & $5,72 \mathrm{fg}$ & $8,22 \mathrm{~b}$ & $6,97 \mathrm{c}$ & $2,61 d$ & $2,66 \mathrm{a}-\mathrm{c}$ & $2,63 \mathrm{bc}$ \\
\hline CR 476/65 & 38,72 & $27,79 \mathrm{~b}$ & $34,25 \mathrm{ab}$ & $5,87 \mathrm{def}$ & $6,89 \mathrm{e}$ & $6,38 \mathrm{e}$ & $2,64 \mathrm{c}$ & $2,62 a-c$ & $2,63 \mathrm{bc}$ \\
\hline PI 304269 & 37,85 & $30,64 \mathrm{ab}$ & $34,25 \mathrm{ab}$ & $5,71 \mathrm{fg}$ & $8,18 \mathrm{~b}$ & $6,95 \mathrm{c}$ & $2,74 \mathrm{~b}$ & $2,81 \mathrm{al}$ & $2,77 \mathrm{a}$ \\
\hline Yerli & 35,70 & $29,28 \mathrm{ab}$ & $32,49 \mathrm{bc}$ & $6,33 \mathrm{a}$ & $6,42 \mathrm{f}$ & $6,38 \mathrm{e}$ & $2,53 \mathrm{e}$ & $2,64 a-c$ & $2,59 \mathrm{bcd}$ \\
\hline Ortalama & 36,55 & 28,28 & 32,41 & 5,96 & 7,37 & 6,66 & 2,59 & 2,62 & 2,60 \\
\hline \multirow{3}{*}{ Genotipler } & \multicolumn{9}{|c|}{ Yağ Asitleri Kompozisyonu (\%) } \\
\hline & \multicolumn{3}{|c|}{ Oleik Asit } & \multicolumn{3}{|c|}{ Linoleik Asit } & \multicolumn{3}{|c|}{ Linolenik Asit } \\
\hline & 2015 & 2016 & Ort. & 2015 & 2016 & Ort. & 2015 & 2016 & Ortalama \\
\hline Ames 26686 & $17,77 \mathrm{a}$ & $16,39 \mathrm{~b}$ & $17,08 \mathrm{a}$ & $18,38 \mathrm{~b}$ & $18,49 \mathrm{~cd}$ & $18,43 \mathrm{c}$ & $38,80 \mathrm{bc}$ & $36,63 \mathrm{e}$ & $37,72 \mathrm{~d}$ \\
\hline Vniimk 17 & $16,16 \mathrm{bcd}$ & $13,56 \mathrm{f}$ & $14,86 \mathrm{~g}$ & $20,20 \mathrm{a}$ & $19,24 \mathrm{~b}$ & $19,72 \mathrm{~b}$ & $36,64 \mathrm{f}$ & $37,52 \mathrm{c}$ & $37,08 \mathrm{e}$ \\
\hline CR 1674190 & $17,93 a$ & $16,50 \mathrm{~b}$ & $17,22 \mathrm{a}$ & $17,05 \mathrm{c}$ & $18,09 \mathrm{~d}$ & $17,57 \mathrm{de}$ & $37,35 \mathrm{e}$ & $35,65 \mathrm{l}$ & $36,50 \mathrm{f}$ \\
\hline Ames 26673 & $17,38 \mathrm{a}$ & $15,15 \mathrm{~cd}$ & $16,26 \mathrm{c}$ & $17,28 \mathrm{c}$ & $17,26 \mathrm{e}$ & $17,27 \mathrm{e}$ & $37,86 \mathrm{de}$ & $36,22 \xi$ & $37,04 \mathrm{e}$ \\
\hline Ames 26676 & $15,80 \mathrm{~d}$ & $15,51 \mathrm{c}$ & $15,65 \mathrm{ef}$ & $18,13 \mathrm{~b}$ & $18,15 \mathrm{~d}$ & $18,14 \mathrm{c}$ & $39,19 \mathrm{~b}$ & 34,50 & $36,84 \mathrm{ef}$ \\
\hline Ames 26680 & $16,70 \mathrm{~b}$ & $15,39 \mathrm{c}$ & $16,05 \mathrm{~cd}$ & $18,46 \mathrm{~b}$ & $18,26 \mathrm{~d}$ & $18,36 \mathrm{c}$ & $37,98 \mathrm{de}$ & $37,32 \mathrm{c}$ & $37,65 \mathrm{~d}$ \\
\hline Ames 28372 & $15,88 \mathrm{~cd}$ & $13,68 \mathrm{f}$ & $14,78 \mathrm{~g}$ & $17,50 \mathrm{c}$ & $18,75 \mathrm{c}$ & $18,13 \mathrm{c}$ & $40,33 a$ & $38,79 \mathrm{~b}$ & $39,56 \mathrm{~b}$ \\
\hline Ames 26665 & $16,39 \mathrm{bc}$ & $14,99 \mathrm{de}$ & $15,69 \mathrm{ef}$ & $16,93 \mathrm{~cd}$ & $18,08 \mathrm{~d}$ & $17,50 \mathrm{de}$ & $40,85 \mathrm{a}$ & 39,$41 ;$ & $40,13 \mathrm{a}$ \\
\hline Ames 26667 & $16,72 b$ & $17,14 \mathrm{a}$ & $16,93 \mathrm{ab}$ & $16,48 \mathrm{~d}$ & $15,60 \mathrm{f}$ & $16,04 \mathrm{f}$ & $40,25 \mathrm{a}$ & $36,81 \mathrm{c}$ & $38,53 \mathrm{c}$ \\
\hline CR 476/65 & $17,88 \mathrm{a}$ & $15,44 \mathrm{c}$ & $16,66 \mathrm{~b}$ & $17,42 \mathrm{c}$ & $18,12 \mathrm{~d}$ & $17,77 \mathrm{~d}$ & $38,28 \mathrm{~cd}$ & $38,31 \mathrm{c}$ & $38,29 \mathrm{c}$ \\
\hline PI 304269 & $16,38 \mathrm{bc}$ & $14,65 \mathrm{e}$ & $15,52 \mathrm{f}$ & $18,64 \mathrm{~b}$ & $17,58 \mathrm{e}$ & $18,11 \mathrm{c}$ & $38,75 b c$ & $36,45 \mathrm{fg}$ & $37,60 \mathrm{~d}$ \\
\hline Yerli & $16,55 b$ & $15,22 \mathrm{~cd}$ & $15,88 \mathrm{de}$ & $20,25 \mathrm{a}$ & $20,41 \mathrm{a}$ & $20,33 a$ & $36,00 \mathrm{f}$ & $36,14 \xi$ & $36,07 \mathrm{~g}$ \\
\hline Ortalama & 16,80 & 15,30 & 16,05 & 18,06 & 18,17 & 18,11 & 38,52 & 36,98 & 37,75 \\
\hline \multirow[t]{3}{*}{ Genotipler } & \multicolumn{9}{|c|}{ Yağ Asitleri Kompozisyonu (\%) } \\
\hline & \multicolumn{3}{|c|}{ Eicosenoik (Gondoic) Asit } & \multicolumn{3}{|c|}{ Araşidik Asit } & \multicolumn{3}{|c|}{ Erusik Asit } \\
\hline & 2015 & 2016 & Ort. & 2015 & 2016 & Ort. & 2015 & 2016 & Ortalama \\
\hline Ames 26686 & $15,12 \mathrm{~g}$ & $17,18 \mathrm{c}$ & $16,15 \mathrm{f}$ & $1,24 \mathrm{f}$ & $1,44 \mathrm{f}$ & $1,34 \mathrm{f}$ & $0,44 \mathrm{~b}$ & $0,55 \mathrm{e}$ & $0,50 \mathrm{~d}$ \\
\hline Vniimk 17 & $16,47 \mathrm{~b}$ & $18,23 \mathrm{~b}$ & $17,35 \mathrm{~b}$ & $1,46 \mathrm{c}$ & $1,62 \mathrm{e}$ & $1,54 \mathrm{e}$ & $0,54 \mathrm{a}$ & $0,59 \mathrm{de}$ & $0,57 \mathrm{~b}$ \\
\hline CR 1674190 & $17,20 \mathrm{a}$ & $17,42 \mathrm{c}$ & $17,31 \mathrm{~b}$ & $1,69 \mathrm{a}$ & $1,85 \mathrm{~d}$ & $1,77 \mathrm{c}$ & $0,44 \mathrm{~b}$ & $0,45 \mathrm{f}$ & $0,45 \mathrm{e}$ \\
\hline Ames 26673 & $17,27 \mathrm{a}$ & $19,06 \mathrm{a}$ & $18,16 \mathrm{a}$ & $1,64 \mathrm{~b}$ & $1,74 \mathrm{de}$ & $1,69 \mathrm{~d}$ & $0,45 \mathrm{~b}$ & $0,56 \mathrm{e}$ & $0,51 \mathrm{~d}$ \\
\hline Ames 26676 & $15,97 \mathrm{cde}$ & $17,32 \mathrm{c}$ & $16,64 \mathrm{~cd}$ & $1,75 \mathrm{a}$ & $2,60 \mathrm{a}$ & $2,17 \mathrm{a}$ & $0,38 \mathrm{c}$ & $0,73 b$ & $0,55 \mathrm{bc}$ \\
\hline Ames 26680 & $16,12 \mathrm{bcd}$ & $16,48 \mathrm{de}$ & $16,30 \mathrm{f}$ & $1,44 \mathrm{c}$ & $1,70 \mathrm{de}$ & $1,57 \mathrm{e}$ & $0,45 \mathrm{~b}$ & $0,57 \mathrm{e}$ & $0,51 \mathrm{~d}$ \\
\hline Ames 28372 & $15,60 \mathrm{ef}$ & $16,74 \mathrm{~d}$ & $16,17 \mathrm{f}$ & $1,34 \mathrm{~d}$ & $1,35 \mathrm{f}$ & $1,35 \mathrm{f}$ & $0,43 \mathrm{~b}$ & $0,62 \mathrm{~cd}$ & $0,53 \mathrm{~cd}$ \\
\hline Ames 26665 & $15,37 \mathrm{fg}$ & $15,94 \mathrm{f}$ & $15,65 \mathrm{~g}$ & $1,45 \mathrm{c}$ & $1,69 \mathrm{e}$ & $1,57 \mathrm{e}$ & $0,37 \mathrm{c}$ & $0,66 \mathrm{c}$ & $0,51 \mathrm{~d}$ \\
\hline Ames 26667 & $16,42 b$ & $17,31 \mathrm{c}$ & $16,86 \mathrm{c}$ & $1,43 \mathrm{c}$ & $1,60 \mathrm{e}$ & $1,51 \mathrm{e}$ & $0,37 \mathrm{c}$ & $0,66 \mathrm{c}$ & $0,52 \mathrm{~d}$ \\
\hline CR 476/65 & $16,23 \mathrm{bcd}$ & $16,55 \mathrm{~d}$ & $16,39 \mathrm{ef}$ & $1,36 \mathrm{~d}$ & $1,64 \mathrm{e}$ & $1,50 \mathrm{e}$ & $0,32 \mathrm{~d}$ & $0,43 \mathrm{f}$ & $0,38 \mathrm{f}$ \\
\hline PI 304269 & $15,85 \mathrm{de}$ & $17,33 \mathrm{c}$ & $16,59 \mathrm{de}$ & $1,60 \mathrm{~b}$ & $2,14 \mathrm{c}$ & $1,87 \mathrm{~b}$ & $0,34 \mathrm{~cd}$ & $0,86 \mathrm{a}$ & $0,60 \mathrm{a}$ \\
\hline Yerli & $16,32 \mathrm{bc}$ & $16,22 \mathrm{ef}$ & $16,27 \mathrm{f}$ & $1,49 \mathrm{c}$ & $2,36 \mathrm{~b}$ & $1,92 \mathrm{~b}$ & $0,54 a$ & $0,58 \mathrm{e}$ & $0,56 \mathrm{bc}$ \\
\hline Ortalama & 16,16 & 17,15 & 16,65 & 1,49 & 1,81 & 1,65 & 0,42 & 0,61 & 0,51 \\
\hline
\end{tabular}

*aynı harf ile gösterilen ortalamalar arasında istatistiki anlamda farklılık yoktur.

Oleik asit oranının, ortalama olarak ilk y1l \%16.80, ikinci y1 \%15.30 ve iki y1lın ortalaması olarak \%16.05 olduğu belirlenmiştir. Genotip bazında değerlendirildiğinde; 2015 yllında en yüksek oleik asit oranına \%17.93 ile CR-1674190 genotipinden, en düşük oleik asit oran 1 ise $\% 15.80$ ile Ames-26686 genotipinden elde edilmiştir. 2016 yllında en yüksek oleik asit oran1 \%17.14 ile Ames-26667 genotipinden, en düşük oleik asit oranı \%13.56 ile Vniimk-17 genotipinden elde ediliş̧tir. İki yılın ortalaması olarak en yüksek oleik asit oranı \%17.22 ile CR-1674190 genotipinden, en düşük oleik asit oran1 \%14.78 ile Ames-28372 genotipinden elde edilmiştir (Çizelge 1).

Linoleik asit oranının, ortalama olarak ilk yıl $\% 18.06$, ikinci yıl \%18.17 ve iki yılın ortalaması olarak
\%18.11 olduğu belirlenmiştir. Genotip bazında değerlendirildiğinde; 2015 yllında en yüksek linoleik asit oranı \%20.25 ile Yerli genotipinden, en düşük linoleik asit oranı se \%16.48 ile Ames-26667 genotipinden elde edilmiştir. 2016 y1lında en yüksek linoleik asit oran1 \%20.41 ile Yerli genotipinden, en düşük linoleik asit oranı $\% 15.60$ ile Ames-26667 genotipinden elde edilmiştir. İki yılın ortalaması olarak en yüksek linoleik asit oranı $\% 20.33$ ile Yerli genotipinden, en düşük linoleik asit oranı ise $\% 16.04$ ile Ames-26667 genotipinden elde edilmiştir (Çizelge 1).

Linolenik asit oranının, ortalama olarak ilk yıl $\% 38.52$, ikinci y11 \%36.98 ve iki yılın ortalaması olarak $\% 37.75$ olduğu belirlenmiştir. Genotip bazında değerlendirildiğinde; 2015 yllında en yüksek linolenik 
asit oran1 \%40.85 ile Ames-26665 genotipinden, en düşük linolenik asit oranı se $\% 36.00$ ile Yerli genotipinden elde edilmiștir. 2016 yılında en yüksek linolenik asit oranı \%39.41 ile Ames-26665 genotipinden, en düşük linolenik asit oranı \%35.40 ile Ames-26676 genotipinden elde edilmiştir. İki yılın ortalaması olarak en yüksek linolenik asit oranı $\% 40.13$ ile Ames-26665 genotipinden, en düşük linolenik asit oranı ise \%36.75 ile yerli genotipinden elde edilmiştir (Çizelge 1).

Eicosenoik asit oranının, ortalama olarak ilk yl $\% 16.16$, ikinci yıl \%17.15 ve iki y1lın ortalaması olarak \%16.65 olduğu belirlenmiştir. Genotip bazında değerlendirildiğinde; 2015 yllında en yüksek eicosenoik asit oran1 \%17.27 ile Ames-26673 genotipinden, en düşük eicosenoik asit oranı se \%15.12 ile Ames-26686 genotipinden elde edilmiştir. 2016 yllında en yüksek eicosenoik asit oranı \%19.06 ile Ames-26673 genotipinden, en düşük eicosenoik asit oranı \%15.94 ile Ames-26665 genotipinden elde edilmiştir. İki yllın ortalaması olarak en yüksek eicosenoik asit oranı $\% 18.16$ ile Ames-26673 genotipinden, en düşük eicosenoik asit oranı ise \%15.65 ile Ames-26665 genotipinden elde edilmiştir (Çizelge 1).

Araşidik asit oranının, ortalama olarak ilk yıl \%1.49, ikinci yıl \%1.81 ve iki yılın ortalaması olarak \%1.65 olduğu belirlenmiştir. Genotip bazında değerlendirildiğinde; en yüksek araşidik asit oranı 2015 yllinda \%1.69 ile CR-1674190 genotipinden, 2016 yllında \%2.60 ile Ames-26676 genotipinden ve iki y1lın ortalaması olarak en yüksek araşidik asit oranı \%2.17 ile Ames-26676 genotipinden elde edilmiştir (Çizelge 1).

Erusik asit oranının, ortalama olarak ilk yıl \%0.42, ikinci yıl \%0.61 ve iki yılın ortalaması olarak \%0.51 olduğu belirlenmiştir. Genotip bazında değerlendirildiğinde; en yüksek erusik asit oranı 2015 yllinda \%0.54 ile Vniimk-17 ve Yerli genotiplerinden, 2016 yllinda \%0.86 ile PI-304269 genotipinden ve iki yılın ortalaması olarak en yüksek erusik asit oranı $\% 0.60$ ile PI-304269 genotipinden elde edilmiştir (Çizelge 1).

Ketencikte daha önce yapılan araştırmalarda; palmitik asit oranının \%5.54-14.12 (Sampath, 2009), \%5.89-7.04 (Katar ve ark., 2012) ve \%5.04-6.20 (Arslan ve ark., 2014), stearik asit oranının \%3.27-4.62 (Sampath, 2009), \%2.50-2.98 (Katar ve ark., 2012)ve \%2.60-2.88 (Arslan ve ark., 2014),oleik asit oranının \%14.01-19.50 (Budin ve ark., 1995), \%10.08-20.12 (Sampath, 2009), \%16.03-17.59 (Katar ve ark., 2012) ve \%15.89-19.65 (Arslan ve ark., 2014), linoleik asit oranının \%18.80-24.00 (Budin ve ark., 1995), \%10.1424.31 (Sampath, 2009), \%18.45-23.36 (Katar ve ark., 2012) ve \%17.13-21.49 (Arslan ve ark., 2014),linolenik asit oranı \%27.00-34.70 (Budin ve ark., 1995), \%35 (Agegnehu ve Honermeier, 1997), \%16.28-25.04 Sampath (2009), \%24.86-32.26 (Katar ve ark., 2012) ve \%25.41-34.28 (Arslan ve ark., 2014), eikosenoik (gondoik) asit oranının \%12.00-14.90 (Budin ve ark., 1995), \%9.70-15.04 (Sampath, 2009), \%13.96-14.84 (Katar ve ark., 2012) ve \%13.78-22.94 (Arslan ve ark.,
2014), erusik asit içeriğinin \%0.00-4.00 (Budin ve ark., 1995), \%0.18-5.3 (Sampath, 2009), \%2.87-3.49 (Katar ve ark., 2012) ve \%2.56-3.14 (Arslan ve ark., 2014), araşidik asit oranının \%1.54-2.83 (Katar ve ark., 2012), \%1.41-1.76 (Arslan ve ark., 2014) arasında değiştiği bildirilmiștir. Bildirilen bu sonuçlar, bu araştırmada elde edilen sonuçlarla uyumlu olup, paralellik arz etmektedir.

\section{SONUC}

Araştırma sonucu ham yağ ve yă asitleri kompozisyonu dikkate alındığında; en yüksek ham yă oranına sahip genotipin Ames-26686 olduğu; oleik asiti yüksek ve yağın yemeklik kalitesini yükseltmek amacıyla çalışmalarda yer alabilecek ketencik genotipinin CR-1674190 olduğu, Linoleik asit oranı bakımından yerli, Omega-3 kaynağı olarak kullanılacak ketencik genotipi olarak Ames-26665 genotipi olduğu ve erusic asit içeriği bakımından da en düşük erusik asit oranına sahip genotipin CR-476/65 olduğu belirlenmiștir. Dolayısıyla yapılacak çalıșmalarda bu genotipler üzerinde durulmasının uygun olduğu sonucuna varılmıștır.

\section{KAYNAKLAR}

Anon 2017. ANKOM Technology Method Analytical Procedure XT10/XT10i/XT15/XT15i (www.ankom.com, erișim 13.07.2017).

Agegnehu M, Honermeier B 1997. Effects of Seeding Rate and Nitrogen Fertilization on Seed Yield, Seed Quality and Yield Components of False Flax (Camelina sative L.). Die Bodenkultur, 48 (1).

Angelini LG, Moscheni E, Colonna G, Belloni P, Bonari E 1997. Variation in agronomic characteristic sand seed oil composition of new oil seed crops in centralItaly. Ind Crops Prod 6:313-323.

Arslan Y, Subașı İ, Katar D, Kodaş R, Kervanoğlu H 2014. Farkli Azot ve Fosfor Dozlarinin Ketencik Bitkisi (Camelina Sativa (L.) Crantz)'nin Bazi Bitkisel Özellikleri Üzerine Olan Etkisinin Belirlenmesi., Anadolu Tarım Bilim. Derg., 2014,29(3):231-239.

Berti M, Wilckens R, Fischer S, Solis A, Johnson B 2011. Seeding Date Influence on Camelina Seed Yield, Yield Components and Oil Content in Chile Vol. 34: 1358-1365.

Budin JT, Brene WM, Putnam DH 1995. Some composition alproperties of Camelina (Camelina sativa L. Crantz) seeds and oils. Journal of the American Oil Chemists 'Society 72: 309-315.

Karahoca A 2002. Çukurova Koşullarında Ketencik (Camelina sativa)'te Farklı Azot ve Fosfor Gübrelemesinin Tohum Verimi ve Yağ Oranına Etkileri. Çukurova Üniversitesi Fen Bilimleri Enstitüsü. Yüksek Lisans Tezi., Adana.

Katar D, Arslan Y, Subașı İ 2012. Ankara Ekolojik Koşullarında Farklı Ekim Zamanlarının Ketencik (Camelina sativa (L.) Crantz) Bitkisinin Yağ Oranı ve Bileşimi Üzerine Olan Etkisinin Belirlenmesi. Tekirdağ Ziraat Fakültesi, Journal of Tekirdag Agricultural Faculty, 9(3):84-90, 2012. 
Kurt O 2015. Bitki Islahı Ders Kitabı, Ondokuz Mayıs Üniversitesi Ziraat Fakültesi Yayınları, No:43.

Kurt O, Uysal H, Demir A, Özgür Ü, Kılıç R 2011. Samsun Ekolojik Koşullarına Adapte Olabilecek Kışlık Aspir (Carthamus tinctorius L.) Genotioplerinin Belirlenmesi Üzerinde Bir Araștırma. Anadolu Tarım Bilim. Derg., 26(3):212216.

Sampath A 2009. Chemical characterization of camelina seed oil. The degree of Master of Science. New Brunswick, New Jersey. p180.

Tomas L, Jaroslav H, Jiri M, Johann V, Jiri VP, Radek F, Ladislav V, Ladisla D, Anna M 2011. Effect of
Combined Nitrogen and Sulphur Fertilization on Yield and Qualitative Parameters of Camelina sativa [L.] Crtz. (false flax). Vol:6, 313-321.

Vollmann J, Damboeck A, Eckl A, Schrems H, Ruckenbauer P 1996. Improvement of Camelina sativa, an underexploited oilseed. p. 357-362. In: J. Janick (ed.), Progress in new crops. ASHS Press, Alexandria, VA.

Zubr J 2003. Qualitative variation of Camelina sativa seed from different locations.,Ind. Crops Prod., 17:161-169. 